\title{
Early Adolescence Today: A Theoretical Approach to Particularities and Challenges
}

\author{
Sara-Debora Topciu \\ University of Oradea, ROMANIA \\ Faculty of Socio-Human Sciences, Doctoral School of Sociology
}

Received: 12 June 2020 - Accepted: 19 November 2020 - Published Online: 8 December 2020

\begin{abstract}
This paper aims to present the main features of early adolescence today (also known as preadolescence). The paper refers to this age period on three levels: the physical level and sexual maturation, the cognitive level, and the socio-emotional level. Thus, we propose a theoretical approach to the main characteristics of early adolescence, but also the analysis of a series of particularities and challenges specific to this stage of life. Despite the fact that childhood, preadolescence and adolescence are certainly difficult, most young people manage to get through these stages of development due to the relationships with family and friends, motivated by academic success or activities that help them build their personality and self-esteem.
\end{abstract}

Keywords: early adolescence, physical level and sexual maturation, cognitive level, socioemotional level.

\section{Introduction}

The early adolescence (or preadolescence) period, considered to be usually in the age range of 10-13 years, is bordered by two other important periods in human development: childhood and adolescence. In this article we propose a theoretical approach to the main characteristics of early adolescence, but also the analysis of a series of particularities and challenges specific to this stage of life. At the same time, we will refer to this age period on three levels: the physical level and sexual maturation, the cognitive level, the socio-emotional level.

\section{Physical level and sexual maturation}

We believe that, given the relatively small number of studies on early adolescence, on the particularities and the challenges that characterize this distinct stage of development, it is necessary, for a good understanding of these, to turn our attention to a wider range of studies which deal in parallel with the other two stages of human existence that frame early adolescence (preadolescence): childhood and adolescence.

Being concerned with the emotional problems that occur in preadolescents, Alves (2013) argues that, in order to complete the relatively limited researches on the emotional problems in preadolescence, it is necessary to rely on a research corpus regarding both childhood and adolescence. And this is because the amount of information about preadolescent emotional

(C) Authors. Terms and conditions of Creative Commons Attribution 4.0 International (CC BY 4.0) apply. Correspondence: Sara-Debora Topciu (PhD candidate), University of Oradea, Doctoral School of Sociology, 1 Universității Street, Oradea, 410087, Bihor County, ROMANIA. E-mail: sdtopciu@gmail.com. 
issues is smaller compared to the amount of data available for adolescence. Secondly, because what is known about the post-childhood stage that precedes adolescence, is added to the knowledge regarding the development of emotional problems in general.

- The early adolescence (or preadolescence) period is usually considered to be in the age range of $10-13$ years.

- Adolescence brings with it countless changes in a person's life. The relatively uniform growth during childhood is suddenly altered by an acceleration of the growth rate.

- The adolescent is in a construction that exposes him in the relationship with the other.

- The relationships with family and friends, accompanied by academic success and activities help children, preadolescents and adolescent build their personality and self-esteem.

However, the adolescence is not necessarily synonymous with problems. It is true that during this period there may be emotional or behavioural changes that, although not particularly annoying, they are consistent themselves (Buchanan et al., 1992).

Adolescence brings with it countless changes in a person's life. The relatively uniform growth during childhood is suddenly altered by an acceleration of the growth rate. To this, we add hormonal, cognitive and emotional changes. Given that all these changes create special nutritional needs, adolescence is considered a vulnerable period of life, especially from a nutritional point of view, as there is a high demand for nutrients due to growth and physical development; it also changes the lifestyle and the eating habits of the teenagers. In addition, those who practice sports or who suffer from a chronic illness follow a strict diet or consume alcohol and drugs, require a special attention from this point of view (Spear, 2002).

According to Lunde (2009), the early adolescence is a period in which both girls and boys risk becoming more and more dissatisfied with the way they look (satisfaction with their own body). Depending on the gender, the preadolescents react differently to the experiences of victimization of the colleagues. The boys who are especially teased about their appearance tend to think that others don't find them attractive. On the other hand, for the girls, a higher frequency of peer victimization experiences tends to affect especially the assessment of the body weight.

It has been determined that there are significant associations among the onset of puberty (pubertal timing), issues regarding body image and self-esteem. At the applicative level, the same research suggests that improving the self-esteem of the preadolescent girls could be made possible by changing the way they see and cope with the different aspects of physical development. The educational strategies could help girls to understand and see in a positive way the physical, psychological, and social changes their bodies undergo during puberty, thus reducing their likelihood of experiencing a negative body image or a low self-esteem (Williams \& Currie, 2000).

Simultaneously, another study concerned with the timing of the onset of puberty (pubertal timing) has indicated that it is more strongly associated with educational attainment and orientation towards achievement than the pubertal status. It is of real interest the fact that, according to the same research, the boys who mature later had the poorest results, while the girls with late maturation had the best results (Dubas et al., 1991).

Regarding sexual maturation, one study states that a normal or a deviant sexuality of the preadolescents and adolescents is related to other behavioural developments that occur simultaneously. These include individual behaviours such as alcohol or drug use/abuse, school failures or successes and the development of social skills. Although it is recognized that the normal and abnormal sexual behaviours of the adolescents and even of the adults originate in the preadolescent development, this aspect is often ignored (Araji, 2004). 
The reactions to sexual intimacy are an integral part of attachment patterns. An attitude of security in attachment promotes intimacy and communication; the fear of attachment, on the other hand, includes general concerns about rejection and abandonment, which are easily transposed into sexual situations. Similarly, avoiding attachment causes a state of discomfort caused by the physical closeness and psychological intimacy specific to sexual intimacy. The research on these issues has concluded, among other things, that the attachment manner is linked to the emotions experienced during sexual episodes, thus, the adolescents with a safe attitude enjoying sexual intimacy significantly more than those who are anxious (fearful) and those with an avoidance attitude (Tracy et al., 2003).

The physical level and sexual maturation also include health issues. When thinking about this, most people associate this term with doctors and hospitals. Therefore, a good level of health can mean for them the absence of the disease. However, the notion of health encompasses many components, including the satisfactory level of physical and mental health of a person and the extent to which individuals in a society are able to live healthy and prosperous lives. Anyway, a healthy society too is not the one that waits for people to get sick, but one that notices the way health is shaped by social, political, economic, cultural, commercial and environmental factors and takes measures for the well-being of the present and future generations. A good health is a fundamental human right, and was presented in 1948 in the well-known Universal Declaration of Human Rights (art. 25) of the United Nations Organization. However, the initiative of Sir William Beveridge from 1942 is less known. He published a report denouncing the lack of healthy housing and the public health problems of the time, such as malnutrition and making recommendations aimed at combating unemployment and childcare measures. His action has acted as a catalyst of the movement to equalize society (Lovell \& Bibby, 2018).

\section{Cognitive level}

According to Kaestner (2009), the cognitive ability of the adolescent, along with a noncognitive trait, namely self-esteem - has a significant and direct association with health in adulthood. For men, the cognitive ability and self-esteem are more correlated with health than to income. For women, on the other hand, cognitive ability correlates less with health and earnings.

At the same time, it has been stated that, in addition to cognitive and motivational variables, the academic achievement is affected by indicators such as popularity and parental involvement. Along with the teachers, who provide the tools needed to improve students' performance, the parents and the colleagues are also variables that can be seen as either a support or an obstacle to achieving better school performance. Also, when it is intended to predict educational achievement, the non-cognitive variables are as significant as the cognitive variables (Veas et al., 2015).

Regarding the changes in the social behaviour, a group of researchers showed that they are determined by both social and biological factors. Thus, during adolescence, it is possible that the peer interactions and societal influences, as well as the genetically determined hormonal framework, influence social behaviour; moreover, the brain matures considerably during adolescence, which has prompted the emergence of a number of evidences that have indicated the role of neural maturation in the development of social cognition during adolescence (Choudhury et al., 2006).

The social competence is seen by the authors of a study as a key feature of noncognitive ability in toddlers. Social competence includes both the ability to complete tasks and manage responsibilities, and the skills needed to control social and emotional experiences. This can be assessed, the authors add, by educators, who observe many situations in which children have to manage relationships with their peers and adults. The school environment offers the 
opportunity to observe children's abilities to interact interpersonally while cooperating with the others to complete daily tasks and to solve conflicts. Such skills, the study notes, are important for progress in the early years of study (Jones et al., 2015).

\section{Socio-emotional level}

Difficulties of internalization and outsourcing - these are the two major categories in which the most common forms of psychopathology that occur in childhood and adolescence, have been included. Thus, while outsourcing difficulties are characterized by harmful and disruptive behaviours directed at others, the internalizing disorders involve a disorder in punitive internal emotions and moods (feelings of sadness, guilt, fear, and worry). In fact, both types of dysfunction have behavioural and affective components, as well as specific cognitive characteristics (ZahnWaxler et al., 2000)

The adolescent is in a construction that exposes him in the relationship with the other. Whether it is about the relationship with family, school, friends and social environment in general - the signs of depression onset (emotional difficulties) can be found in the context of changing this relationship. Manifestations may occur in three main areas of adolescents' lives: at school, in extracurricular activities and in relationships. At school, the study participants reported deterioration in their academic performance, partly due to difficulties in understanding and focussing that have contributed to their exhaustion and discouragement. In terms of free time, there is a decrease and then a loss of pleasure in carrying out previously satisfying activities. Relational life: some participants mentioned going through a particularly painful state in their relationships. During their experiences, they stated the feeling of being different from others, isolated in their suffering and often chose loneliness instead of relating to others, among whom the persistent and painful feeling of isolation did not subside (Révah-Lévy et al., 2012).

At the micro level, the preadolescents are affected by what happens in the families in which they grow up. Because preadolescence is a unique and important stage in an individual's development, the family plays a crucial role in socializing and cultivating preadolescent values. Therefore, family conflict has effects on his relating capacity and feeling of autonomy of the preadolescent and is related to his externalization through antisocial behaviour and aggression (less verbal aggression) (Kader \& Roman, 2018). The manifestation of such reactions towards the undesirable family climate, undoubtedly leads to a decrease in the level of social and emotional well-being of the preadolescents.

The relationship with grandparents is also very important. According to a study, adolescents perceive their grandparents as relevant figures outside their immediate family, who play an active role in the lives of their grandchildren. Therefore, grandparents can be quite a resource in supporting adolescents and stabilizing family life (Attar-Schwartz et al., 2009).

The Report of the children and young people's health outcomes forum - Mental health sub-group (2012) reaffirms that a child's early experiences lay the foundations for his or her future life chances. He or she develops more harmoniously if he/she is cared for in a way that shows "safety, warmth and receptivity" (p. 4). Such an approach supports their healthy growth and allows them to acquire the basic skills of emotional adjustment and social communication, as well as the ability to learn more easily, to develop better social relationships, while reducing the chances of further risk behaviour (Ibid., 2012).

Regarding the parenting style used by parents, we note its influence on children's development path. The latter reveals, later, what kind of teenagers make up today's society, what traits they have and what challenges they face. 
The results of the study conducted by Aunola and her team show that parenting style plays an important role in developing strategies for success by adolescents. It seems that the family relationships that emphasize, on the one hand, the child's discovery and trust in parents and their involvement, and, on the other hand, the control and monitoring of children by parents, tend to favour the development of strategies aimed at achieving success; conversely, family relationships characterized by lack of involvement, lack of parental trust and parental control, seem to lead to strategies doomed to failure. However, as the school achievements are the foundation of adolescents' subsequent success in socializing during adulthood, the impact of parenting style can have long-term consequences for adolescents' general development (Aunola et al., 2000)

The study of Fosco and his collaborators highlights the importance of considering parental practices and family relationships (relationships with parents and siblings) as factors that determine the development of a difficult/risky behaviour of the young person. It also emphasizes the contribution of parenting practices, parent-child relationships and sibling conflict in the development of the young person's problematic behaviour. The research's results suggest that the interventions aimed at reducing the risk of adolescents participating in antisocial behaviours, avoiding substances use and preventing deviant friendships can be improved if they promote a good father-son relationship (whether the young man lives with the biological father or not) and are oriented towards mitigating conflicts between siblings (Fosco et al., 2012).

According to a study, although it may be difficult for the parents to remain involved in the lives of their preadolescents, given the complexity of the modern life, of the changes that take place during preadolescence and of the impersonal climate of many schools, still, by overcoming these obstacles, parents can contribute to facilitate the adaptation and the involvement of children in the school environment. The challenge of the preadolescents' parents, the authors add, is to find ways to stay active in their children's lives, while leaving room for friendships. The latter are an important source of influence on adolescent's behaviour, and parents can exert some influence on the choice and development of friendships during this period (Simons-Morton \& Chen, 2009).

\section{Take-home message}

As a conclusion, we may say that, despite the fact that childhood, preadolescence and adolescence are certainly difficult, most young people manage to get through these stages of development due to the relationships with family and friends, motivated by academic success or activities that help them build their personality and self-esteem.

\section{Acknowledgements}

This research did not receive any specific grant from funding agencies in the public commercial, or not-for-profit sectors.

The author declares no competing interests. 


\section{References}

Alves, D. E. (2013). Emotional problems in preadolescence: Immigrant background, school difficulties, and family factors [Doctoral Dissertation, University of Oslo]. DUO Research Archive. https://www.duo.uio.no/bitstream/handle/10852/39845/dravhandlingalves.pdf? sequence $=1 \&$ isAllowed $=\mathrm{y}$.

Araji, S. K. (2004). Preadolescents and adolescents: Evaluating normative and non-normative sexual behaviours and development. In G. O’ Reilly, W. L. Marshall, A. Carr \& R. Beckett (Eds.), The handbook of clinical intervention with young people who sexually abuse (pp. 3-35). Psychology Press.

Attar-Schwartz, S., Tan, J.-P., \& Buchanan, A. (2009). Adolescents' perspectives on relationships with grandparents: The contribution of adolescent, grandparent, and parent-grandparent relationship variables. Children and Youth Services Review, 31(9), 1057-1066. https://doi.org/10.1016/j.childyouth.2009.05.007

Aunola, K., Stattin, H., \& Nurmi, J.-E. (2000). Parenting styles and adolescents' achievement strategies. Journal of Adolescence, 23(2), 205-222. https://doi.org/10.1006/jado.2000.0308

Buchanan, C. M., Eccles, J. S., \& Becker, J. B. (1992). Are adolescents the victims of raging hormones: Evidence for activational effects of hormones on moods and behavior at ddolescence. Psychological Bulletin, 111(1), 62-107. https://doi.org/10.1037/0033-2909.111.1.62

Children and Young People's Health Outcomes Forum (2012). Report of the children and young people's health outcomes forum - Mental health sub-group. https://assets.publishing.service.gov.uk/government/uploads/system/uploads/attachment data/file/216853/CYP-Mental-Health.pdf.

Choudhury, S., Blakemore, S.-J., \& Charman, T. (2006). Social cognitive development during adolescence. Social Cognitive and Affective Neuroscience, 1(3), 165-174. https://doi.org/10.1093/scan/nslo24

Dubas, J. S., Graber, J. A., \& Petersen, A. C. (1991). The effects of pubertal development on achievement during adolescence. American Journal of Education, 99(4), 444-460. https://doi.org/10.1086/443993

Fosco, G. M., Stormshak, E. A., Dishion, T. J., \& Winter, C. (2012). Family relationships and parental monitoring during middle school as predictors of early adolescent problem behavior. Journal of Clinical Child and Adolescent Psychology, 41(2), 202-213. http://doi.org/10.1080/15374416.2012.651989

Jones, D. E., Greenberg, M., \& Crowley, M. (2015). Early social-emotional functioning and public health: The relationship between kindergarten social competence and future wellness. American Journal of Public Health, 105(11), 2283-2290. https://doi.org/10.2105/ajph.2015.302630

Kader, Z., \& Roman, N. (2018). The effects of family conflict on the psychological needs and externalising behaviour of preadolescents. Social Work, 54(1), 37-52. https://doi.org/10.15270/54-1-613

Kaestner, R. (2009). Adolescent cognitive and non-cognitive correlates of adult health. NBER Working Paper No. 14924. https://www.nber.org/papers/w14924.pdf.

Lovell, N., \& Bibby, J. (2018). What makes us healthy? An introduction to the social determinants of health. Health Foundation. https://www.health.org.uk/sites/default/files/What-makes-us-healthyquick-guide.pdf.

Lunde, C. (2009). What people tell you gets to you: Body satisfaction and peer victimization in early adolescence [Doctoral Dissertation, University of Gothenburg]. Gothenburg University Publications Electronic Archive. http://hdl.handle.net/2077/19350. 
Révah-Lévy, A., Falissard, B., \& Moro, M. R. (2012). La dépression de l'adolescent: De la recherche qualitative à la mesure. La psychiatrie de l'enfant, 55(2), 607-635. https://www.cairn.info/revue-la-psychiatrie-de-l-enfant-2012-2-page-607.htm.

Simons-Morton, B. G., \& Chen, R. (2009). Peer and parent influences on school engagement among early adolescents. Youth \& Society, 41(1), 3-25. https://doi.org/10.1177/0044118X09334861

Spear, B. A. (2002). Adolescent growth and development. Journal of the American Dietetic Association, Supplement, 102(3), S23-S29. https://doi.org/10.1016/S0002-8223(02)90418-9

Tracy, J. L., Shaver, P. R., Albino, A. W., \& Cooper, M. L. (2003). Attachment styles and adolescent sexuality. In P. Florsheim (Ed.), Adolescent romantic relations and sexual behavior: Theory, research, and practical implications (pp. 137-159). Lawrence Erlbaum Associates Publishers.

Veas, A., Castejón, J.-L., Gilar, R., \& Miñano, P. (2015). Academic achievement in early adolescence: The influence of cognitive and non-cognitive variables. The Journal of General Psychology, 142(4), 273-294. https://doi.org/10.1080/00221309.2015.1092940

Williams, J. M., \& Currie, C. (2000). Self-esteem and physical development in early adolescence: Pubertal timing and body image. Journal of Early Adolescence, 20(2), 129-149. https://doi.org/10.1177/0272431600020002002

Zahn-Waxler, C., Klimes-Dougan, B., \& Slattery, M. J. (2000). Internalizing problems of childhood and adolescence: Prospects, pitfalls, and progress in understanding the development of anxiety and depression. Development and Psychopathology, 12(3), 443-466. https://doi.org/10.1017/S0954579400003102 
S. D. Topciu - Early Adolescence Today: A Theoretical Approach to Particularities and Challenges

C O A $\mathrm{s}$ 